\title{
Two Early Pillars of Modern Scientific Education in India: The Meaning and Relevance of the Projects of M L Sircar and Asutosh Mookerjee
}

\author{
John Lourdusamy*
}

(Received 2 June 2018)

\begin{abstract}
Mahendra Lal Sircar (who founded the Indian Association for the Cultivation of Science in 1876), and Asutosh Mookerjee (who was instrumental in setting up the University College of Science, Calcutta in 1916), left a lasting impact on the future course of higher scientific education and research in India - not only through the workings of the institutions that they set up, but also through the strong ideas, visions and struggles associated with them as they took shape in the complex interplay of the compulsions of colonialism and rising spirit of nationalism. This essay analyses the differences in the approaches of Sircar and Mookerjee, the commonalities between them, and finally, the lessons that their efforts hold, for today.
\end{abstract}

Key words: Calcutta University, Colonialism, IACS, Nationalism, Philanthropy, Science education, Science popularisation, Swadeshi, UCS.

\section{INTRODUCTION}

In any history of science education in India, Mahendra Lal Sircar (1833-1904) and Asutosh Mookerjee (1864-1924) will occupy a pre-eminent place. Their life and careers explicate the complex evolution of science education through the opportunities and the constraints thrown up by British colonialism. Sircar and Mookerjee represent the different ways in which one had to negotiate with this double-sidedness of colonialism. This essay analyses those differences, the commonalities between them in spite of the slightly different circumstances in which they operated, and finally the lessons that they hold for today.

Sircar, one of the earliest products of the Calcutta Medical College (which itself was a colonial creation - inaugurated in 1835 in the wake of Macaulay's Minute), went beyond his immediate professional call of medical practice, to serve the larger cause of 'cultivating' modern science by creating an awareness of its importance among the public and eliciting their interest and participation. For this he set up the Indian Association for the Cultivation of Science (IACS), in 1876 as a predominantly indigenous enterprise - although he was conscious of the need to depend on the colonial state to a considerable extent.

Mookerjee, likewise was a product of the new colonial educational set up. Although he chose the legal profession, he too served the cause of science education - primarily as ViceChancellor of Calcutta University - a post that was offered to him not only in view of his legal and other capabilities but as a political move in the wake of the shrill voices of nationalism in the early years of the twentieth century. Unlike Sircar, Mookerjee went into the heart of a colonial

\footnotetext{
* Department of Humanities and Social Sciences, Indian Institute of Technology, Madras, Chennai- 600036, Email: jblsamy@iitm.ac.in
} 
establishment and tried to effect changes from within, which among other things, resulted in the foundation of the University College of Science (UCS) in 1916.

The IACS and UCS were institutions of modern science, but they signified something larger. They point to the creation of a new culture of science, and stand as embodiments of strong convictions about the social significance, meaning and place of modern science in India's destiny.

\section{Sircar AND the IACS}

Sircar joined the Calcutta Medical College in 1854 and got his L.M.S. (Licentiate in Medical Science) in 1860 and M.D. degree in 1863. The Medical College was one of the few avenues for exposure to science in general, as it had courses on subjects such as physics, chemistry and botany. But these were peripheral and were open only to the limited few who entered the Medical College. Other colleges either did not have adequate science courses or (like the Presidency College, Calcutta) had some science teaching, but with inadequate laboratory and other facilities. The IACS sought to redress this lacuna and in a more expansive sense, it aimed to create a broad and strong scientific base from which would spring original scientific work (rather than mere learning of science) and upon which technological pursuits could be built. This was in sharp contrast to the colonial state's lukewarm attitude in this regard, as it was interested more in creating lower level mechanics and technicians for its various enterprises than to promote a culture of genuine science education. Sircar's task was rendered more challenging by the attitude of a section of (traditionalist) Indian elite who generally were close to the colonial state by ties of interest and who (under the banner of the 'Indian League'), wished to open an institute primarily for technical training of Indian youth for immediate jobs in industries. Apart from the League's goals being at cross purposes with Sircar's, the Government's (natural) bias towards the League's plan also made it difficult for Sircar to raise funds as the (traditional) wealthy generally tended to patronise causes which had the favour of the colonial state.

With huge disadvantages coming from both the colonial state as well his own countrymen, Sircar continued to campaign vigorously by taking special care to keep the wealthy close to his project - for instance, by including 'every possible influential patron' on the Committee of Management. ${ }^{1}$ This perseverance, particularly complemented by his personal rapport with the Lieutenant Governor of Bengal (Richard Temple), enabled the starting of the IACS on a moderate scale on the $29^{\text {th }}$ July 1876 on a piece of land at Bow Bazaar offered by the Government on promise of investing 50,000 rupees in Government securities. ${ }^{2}$ Temple himself presided over the occasion and while politely offering his good wishes, he drew greater attention to the "factories, both cotton and jute, on both sides of the river...their chimneys...coal mines... and the new fields of iron' which called for the establishment of technical schools and colleges - to which category, he pointed out, the IACS did not belong. ${ }^{3}$ Sircar, for his part, stood steadfast to his larger vision while constantly seeking the support and 'blessings' of the colonial state. With much effort, he was able to raise considerable infrastructure like a lecture hall and research laboratory, the latter being funded single-handedly by the Maharajah of Vizianagram. Scientific instruments and equipment were acquired as permitted by available resources. Through these facilities, the IACS arranged regular lectures and public demonstrations using locally available expertise. The

\footnotetext{
1 The Hindoo Patriot, 18 May 1891.

2 Later, 'to keep [the] principle of independence', Sircar paid the price of the land in full to the Government, Report of the Twenty-Ninth Annual Meeting of the IACS, p.12.

3 'Proceedings of the Inaugural Meeting of The IACS' [29 July 1876] (Sircar, 1880, pp. 143-47)
} 
lectures and demonstrations evinced such interest that students even from the Presidency College flocked to $\mathrm{IACS}^{4}$, as also women from colleges like La Martiniere, Bethune and Calcutta Medical College. ${ }^{5}$ Apart from such lectures, in course of time, the IACS opened its doors to serious researchers to use its laboratory facilities. One such later day researcher was C V Raman whose works in the very precincts of the IACS won the first Nobel Prize in Science for an Indian (in 1930).

\section{MookerJee AND THE UCS}

Mookerjee took his B.A. and M.A. in Mathematics (with distinction) and another M.A. in Physical Science and looked set for a big career in science except that his sense of self-respect made him reject the offer made by the Director of Public Instruction, Sir Alexander Pedler, for a teaching job at the Presidency College - but without the same status and pay as Europeans of the same qualification. Thereafter Mookerjee pursued Law and with a B.L. earned in 1888, started practice in the Calcutta High Court. In 1904 he became a judge and remained one till his retirement in 1923. He however retained his connection with the world of education as Member of the Calcutta University's Syndicate, President of the Board of Studies in Mathematics, and Member of the Universities Commission of 1902. He represented the University on the Bengal Council (1899-1903), and eventually rose to be Vice-Chancellor in 1906 (Mondal, 1933, pp. 6465). He was Vice-Chancellor for four consecutive terms between 1906 and 1914 and for another term from 1921 to 1923 . His long-standing appreciation of science ensured that he used the opportunity to redress from within, the very deficiencies in the colonial educational system that Sircar tried to redress from outside.

Mookerjee assumed the Vice-Chancellorship of Calcutta University when nationalist feelings were running high against the Universities Act of 1904 introduced by Lord Curzon. The Act was seen as an attempt to narrow the base of education by abolishing poor private colleges with strict terms of affiliation. ${ }^{6}$ On the other hand, Mookerjee saw in the Act an opportunity to promote national interests as it envisaged the transformation of the University from a purely examining body into one with facilities for teaching and powers to appoint University Professors and Lecturers, to hold and to manage educational endowments, to erect, equip and maintain University Libraries, Laboratories and Museums (Nurullah and Naik, 1951, pp.463-7).

The growing opposition to the University Act became compounded as it got intertwined with the ill-will generated by Lord Curzon's infamous Partition of Bengal and with the swadeshi movement calling for the boycott of English goods. This call extended to the sphere of education too with the formation of the National Council of Education to promote national schools and colleges (Mukherjee, 1992, p.36). Mookerjee however reckoned that with the colonial Government as the recognising authority and as a major provider of jobs, nationalist efforts in education would not bear much fruit. His stand was vindicated in due course with the NCE gradually losing the initial steam and students realizing the dim prospects of their unrecognized degrees (Ray, 1927, p.171). Meanwhile, Mookerjee gained a firm foothold within the University and (among several initiatives), he laid out a vision for a postgraduate centre for science towards which he effectively was able to attract the patriotic and philanthropic sentiments of the wealthy, who had earlier donated generously to the failed NCE cause (Bose, 1964, p. 308). In 1912, the University received a generous endowment from Taraknath Palit (who was at the

\footnotetext{
${ }^{4}$ Appendix to Report of the Indian Education Commission, Calcutta, 1883, p.367.

5 Report of the Eleventh Annual Meeting of the IACS, 1888, pp.2-3.

${ }^{6}$ Report of the Proceedings of the Nineteenth Indian National Congress, p. 84.
} 
forefront of the earlier nationalist education movement) for the promotion and diffusion of science - pure and applied, by the institution of Professorships in the University and for the training of such Professors abroad if needed. ${ }^{7}$

An important condition in the Deed was that the new chairs were to be occupied by Indians. While providing for the maintenance of the Professorships, it made it incumbent upon the University to provide suitable laboratories, lecture rooms, libraries, museums and workshops. Further endowments flowed - including more from Palit himself and from others like the eminent lawyer and nationalist leader, Rash Behari Ghose - who regretted that he had wasted his gifts on a legal career by not aspiring to be a scientist (Mukherjee, 1953, pp.xi-xii). Interestingly, the new laboratories also acquired apparatus from the failed institutions started under the auspices of the NCE (Majumdar, 1996, p.265). Mookerjee was particular in procuring the best talents for the newly instituted Professorships. For the Palit Professorship of Chemistry he chose the eminent chemist P C Ray and for Physics, he handpicked the future Nobel Laureate, C V Raman, who was at that time working as a government servant in the Finance Department, while also doing private studies and experiments in Physics at the IACS. The other chairs, too, were filled with competent men of proven merit. Such inherent merits attracted many bright young students including future stalwarts like Satyandranath Bose, Meghnad Saha, Sisir Kumar Mitra and Jnanendra Chandra Ghose.

\section{Sircar and MookerJee - The Common Ground}

In spite of the different kinds of institutions that Sircar and Mookerjee started, and the different ways in which they took shape, the efforts were underlined by certain common elements. One such was the approach to modern science itself in terms of its broad significance. For Sircar, modern science, which had raised man, 'from the humble position of minister and interpreter... to the sublime rank of master of Nature' (Sircar, 1880, p.16), was 'best calculated to remove prejudice and the spirit of intolerance from the mind' (Sircar, 1869, p.287). Similarly Mookerjee too admired the 'gigantic strides made by the intellect of man in the conquest of nature', ${ }^{8}$ and believed that modern science with its fostering of critical thinking had a liberating effect on the mind. While both were critical of some of the prevailing prejudices and practices, they also highlighted positive aspects of the Indian heritage - the 'original vigour and energy', which had dimmed in due course (Sircar, 1869, p.288). In fact, what was absorbed from outside had to be sensitive to this rich heritage and add to 'the existing beauties of [the] social life' and to 'strengthen national selfconsciousness' (Pal, p.49).

While underscoring the nationalist sensibilities and also eliciting support from the native elite, both Sircar and Mookerjee also identified their endeavours closely with the colonial masters - by way of acknowledgement, and more importantly, as moral pressure. Sircar for instance projected the IACS not only as an extension of the overall 'progress of enlightenment' under the 'blessings of western education" " but also as a test of the British willingness to fulfil their (self-professed) 'duty'. Interestingly, the first proposed permanent Professorship at IACS was named after a Viceroy - Lord Ripon, who was seen as a 'true friend' of India. ${ }^{10}$ The IACS project, though meant to be an indigenous enterprise, was open to offering its services to the Government, as long as it did not prejudice the basic purposes of the Association.

\footnotetext{
7 University of Calcutta, The Calendar - 1942, p.83.

8 Report of the Twenty-Ninth Annual Meeting of the IACS, pp.41-2.

9 Report of the Fourteenth Annual Meeting of the IACS, 1891, p. 26.

${ }^{10}$ Report of the Fourteenth Annual Meeting of the IACS, 1891, pp.20-1.
} 
In a similar vein, Mookerjee cherished the 'wise dispensation of Providence' through which India's destiny had been united with Britain's. This bond (although a colonial one), enabled India to 'take full advantage of the immense opportunities of advancement' offered by the West.' ${ }^{11}$ However, he too laced this appreciation with reminders to the government of its concomitant responsibilities. On the one hand, he presented his project to the public and local benefactors as an instrument of national welfare to elicit their support as a matter of patriotic duty. On the other, he projected it to the colonial state as a matter of pride to it and worthy of its care. Along with this symbolic act of identification, Mookerjee also tactically co-opted the state into his project by ensuring that the deeds of the endowment (like the ones by Palit and Ghosh) were framed in such a way that they laid on the University the responsibility of providing for the expenses of the buildings, laboratories and maintenance. Mookerjee often pointed to those endowments themselves as exemplars of a responsible attitude - for the government to emulate, in its turn!

Mookerjee and Sircar, were thus adopting a strategy of 'double identification' by identifying their respective projects both with the nationalist feelings as well as with the colonial state for eliciting their respective participation and support. In doing this, and in highlighting the strengths and deficiencies of past heritage and in extolling the 'blessings' of colonial rule, they were advancing an identical intellectual agenda as well as practical strategies, keeping in view the constraints of the existing colonial order.

\section{Sircar and MookerJee - The Divergences}

But there were very significant ways in which the projects of Sircar and Mookerjee differed from each other. In spite of identifying the IACS project with the colonial players, Sircar was very keen on the 'indigenous' aspect of the project as also its independence. Sircar rightly apprehended that if the Government occupied a predominant place in the IACS project, then his distinct and broader agenda would be in jeopardy. Also he firmly believed in the ideal of self-reliance and the need to rid the country of 'its excessive dependence on the Government for everything' (Sircar, 1869, p.291). However, the plain existential realities of colonialism dictated that little could be achieved without the support of the Government which was constant in its evasiveness: 'sympathising' with such aspirations but insisting that the exertions and efforts of "native Gentlemen' - out of 'their own free will for the improvement of their countrymen in scientific knowledge', would do better. ${ }^{12}$ While Sircar operated in this complex paradox, the case of Mookerjee was that of a 'native' who had penetrated into that very colonial establishment whose help (sans interference) Sircar sought from outside. Mookerjee not only had the advantage of being offered the Vice-Chancellorship, and vast prior experience with the University, but also a more conciliatory attitude from the colonial state given the political upheavals of the time. The attitude towards science education as such, had not changed much, but at least the state did not act directly antagonistic to Mookerjee's efforts towards higher scientific teaching and learning. While the colonial state was lukewarm to fund the UCS project itself, Mookerjee could use the moral weight of his well-ensconced position and reputation in the University to raise funds effectively from the native rich. While Sircar struggled with the problem that the wealthy preferred to ally with projects that pleased the colonial state, in Mookerjee's case, he himself (because of being inside a state establishment), in

\footnotetext{
11 'Address by Sir Asutosh Mookerjee', University of Calcutta Special Convocation for Conferring an Honorary Degree on H.R.H. The Prince of Wales on Tuesday, $27^{\text {th }}$ December, 1921, p.4.

${ }^{12}$ Letter from office of the Governor of Bengal to Mahendra Lal Sircar, (Sircar, 1880, p. 51).
} 
a sense, symbolized the colonial state and thus did not face the major impediment that Sircar had. One also has to bear in mind the changed state of affairs between 1870s and early twentieth century. By the time of Mookerjee's efforts, the appreciation of science had sunk considerably deeper and he did not have to exert to the extent that Sircar had to [to convince patrons]. Also the profile of the wealthy sections had changed significantly. While Sircar had to appeal predominantly to land-based feudal traditional elements, Mookerjee could count on the nouveau riche who had amassed wealth through new professions like modern legal practice. Thus Mookerjee did not have the misfortune of having to depend on the colonial state to convince his own countrymen to loosen their purse -strings. Also the nature of the colonial state had changed in the period between IACS and UCS efforts. The growing spirit of nationalism, and the self-inflicted problems of the colonial state (through ill-advised steps like the Partition of Bengal - which was eventually annulled in 1911), made the colonial state more conciliatory. Owing to these changed circumstances, Mookerjee was able to move rapidly in his project. However, in spite of the challenges that beset IACS, it never lost its significance and value.

\section{Conclusion: Lessons for Today}

The ideas and actions of Sircar and Mookerjee towards science and science education hold several lessons for our age. At a time when the world stares at the unenviable consequences of excessive faith in the power of science and of the unwise use of technology, it is useful to recall that in spite of the great admiration that Sircar and Mookerjee had for modern science and the 'power' it granted man over nature, they were able to go beyond the Baconian and mere instrumentalist perspectives. They were able to see in science 'the workings of the power and intelligence and goodness far transcending anything that we can imagine' (Sircar, 1880, p.17), and that its 'eventual worth depended on the wisdom and discretion with which man used it'. ${ }^{13}$ Also at a time when there is a tendency to manifest strains of nativism, it is worthwhile to bear in mind that someone like Mookerjee who toiled hard to accord a prominent place for Indian cultures [apart from science] and to promote vernacular education inside Calcutta University, was at the same time not one to be 'bamboozled by idealistic and roseate pen-pictures of ancient past' (Sarkar, 1932, p.3). He considered it suicidal to 'sit on the lovely snow-capped peaks of the Himalayas absorbed in the contemplations of [the] glorious past'. ${ }^{14}$ On the other hand, these pioneers were particular about Indian selfassertion within the realm of modern science. One needs to ask the poignant question as to why today, our scientists are not confident of the standards of our own scientific journals whereas C V Raman (whose life and work was a living link between the UCS and IACS), published his work in the Indian Journal of Physics - work which could earn a Nobel Prize. Yet another kind of assertion, which is very relevant today, is the assertion of academic independence and of the pre-eminent role of the University in society rather than it being a 'great scholastic sanctuary. ${ }^{\prime}{ }^{15}$

Strong leadership and ability to instill pride and self-confidence in the countrymen are qualities, which are worth emulating today. The moral authority that Mookerjee had was something that even a colonial government could not brush aside. In today's scenario, such leadership as manifested by Sircar and Mookerjee is crucial so that even as the role of the government is

\footnotetext{
${ }^{13}$ A. Mookerjee, 'Address Delivered at the First Convocation of the University of Mysore on 19th October 1918' (Rao, 1930, pp.19-21).

14 A. Mookerjee, 'Address Delivered', p.21.

${ }_{15}$ A. Mookerjee, 'Convocation Address at Calcutta University’ [March 18, 1922], (Sinha, 1970, pp.73-4).
} 
appreciated, academic independence is not compromised by undue interference. The social vision and sense of mission as shown by them is particularly needed today to attract far greater private philanthropy to causes of scientific education, and most importantly, to attract talented expertise and students at a time when (as like the legal profession in the days of Sircar and Mookerjee) there are several 'lucrative' avenues for bright young students whose gifts are underutilised or grossly diverted by their landing up in software, finance and consultancy firms sometimes even after a good degree in science or technology. If Sircar and Mookerjee could accomplish much under an alien, colonial dispensation, their example (as thinkers and institution builders) invites us to introspect as to how larger the scope and potentials are, for today.

\section{BiBLIOGRAPHY}

Bose, D M. Asutosh Mukherhjee - 1864 -1964, Science and Culture, 30.7 (1964): 299-311.

Majumdar, C K, et al (eds.), S N Bose: The Man and His Work, Part II : Life, Lectures and Addresses, Miscellaneous Pieces, S N Bose National Centre for Basic Sciences, Calcutta, 1996.

Mondal, B. Sir Asutosh, Sudhangshu Bhusan Mondal, Calcutta, 1933.
Mukherjee, A. Fifty Years of National Education, National Council of Education, Calcutta, 1992.

Mukherjee, H., Benoy Kumar Sarkar: A Study, Das Gupta, Calcutta, 1953.

Nurullah, Syed and Naik, J P. A History of Education in India, $2^{\text {nd }}$ revised edn., Macmillan, Bombay, 1951.

Pal, B C. Sir Asutosh Mookerjee: A Character Study, Deva Prasad Datta, Calcutta, n.d.

Rao, C H (ed.). Addresses Delivered at the Mysore University Convocations (1918-29), Bangalore Printing \& Publishing Company, Bangalore, 1930.

Ray, Prithwis Chandra, Life and Times of C R Das, Oxford University Press, London, 1927.

Sarkar, B K. Asutosh and His Ambitions for Young Bengal, Chuckervertty, Chaterjee \& Co. Ltd., Calcutta, 1932.

Sinha, S, Asutosh Mookerjee, Publications Division, Ministry of Information and Broadcasting, Govt. of India, New Delhi, 1970.

Sircar, M L. On the Desirability of Cultivation of Sciences by the Natives of India, The Calcutta Journal of Medicine, 2 (1869): 286-91.

Sircar, M L. The Indian Association for the Cultivation of Science, IACS, Calcutta, 1880.

University of Calcutta Special Convocation for Conferring an Honorary Degree on H.R.H. The Prince of Wales on Tuesday, 27 $7^{\text {th }}$ December, 1921, Calcutta, 1921. 